\title{
ESPAÇO URBANO \\ E IMIGRANTES: \\ Porto Alegre na virada do século*
}

Núncia Santoro de Constantino**

Abstract - This article tries to make an analysis of ways of occupation into urban space by immigrants, in Porto Alegre, Brazil, in the turn of twentieth century, starting with the concept of gentrification.

O presente trabalho tem caráter exploratório, analisando a inserção de imigrantes no espaço urbano porto-alegrense. Diz respeito, portanto, a relações sociais e a formas de ocupação deste espaço, como reflexo do processo histórico.

De início, é importante registrar que "no discurso do espaço, não há lugar para o carente de significado [...]". Coelho Netto enfatiza que o mesmo "só pode ser analisado a partir das relações sociais que nele se desenvolvem [...]". ${ }^{1}$ Assim, o espaço recebe uma carga semântica a partir de uma prática, seja real ou imaginária.

De outra parte, o conceito gentrification também poderá ser referência nesta análise, pois define o deslocamento de famílias de classe

* Agradecimentos ao Historiador Dr. Sérgio da Costa Franco e ao Arquiteto Prof. Renato Menegotto, pelas valiosas contribuições, em termos de discussāo e indicaçâo de fontes.

** Doutora em História Social, Docente do IFCH-PUCRS, Porto Alegre, Brasil.

1 J. Teixeira Coelho Neto. A construçâo do sentido na Arquitetura. S. Paulo: Perspectiva, 1984, p. $127,118$. 
média para determinadas áreas urbanas, com a conseqüente valorização das mesmas no mercado, em prejuízo de antigos moradores.

A palavra gentrification foi utilizada por Ruth Glass, no início dos anos sessenta, referindo-se ao afluxo então recente da gentry classe média, seja alta ou baixa, em determinados quarteirões londrinos, antes ocupados pela classe trabalhadora. ${ }^{2}$

Furtado lembra, entretanto, que a conceituação estreita da palavra, como aquela que surgiu nas primeiras tentativas de descrição do processo, precisa ser evitada; o fenômeno deve ser observado a partir de um amplo processo de desenvolvimento urbano, sem fixação em análises empíricas isoladas, a fim de que seja compreendido "um novo padrão de (re)estruturação do espaço [...]". ${ }^{3}$

Atribuindo a espaços algum significado, o Bom Fim representa o bairro dos judeus, Cidade Baixa é bairro de italianos, Floresta é aquele de alemães, Navegantes e São João são bairros operários. Os três primeiros concentram representantes de camadas sociais intermediárias; os dois últimos são bairros populares. Procuro analisar o processo de desenvolvimento urbano de modo amplo, com ênfase nas relações sociais que nele se desenvolvem, justificando a semantização dos mesmos.

Um surto de crescimento verificou-se em Porto Alegre depois de 1850. A Capital dava curso à sua vocação comercial, graças aos excedentes produzidos pelos imigrantes alemães nas colônias às margens do rio dos Sinos.

Fundou-se a Praça do Comércio, embrião da Associação Comercial, o Theatro São Pedro foi inaugurado, a Hydraulica forneceu água a chafarizes e a domicílios. A Guerra do Paraguai oportunizou bons negócios, o sistema ferroviário aproximou mercados.

A-cidade se transformava em cidade, abandonando seu traçado inicial que seguia as normas difundidas pela Aula de Fortificação e Arquitetura Militar, instalada em Lisboa. Em 1680, tal aula foi dirigida por Luís Serrão Pimentel, autor do Método lusitano de desenhar as fortificações das praças regulares, fortes de campanha e outras obras

2 Ruth Glass. London aspects of change. Londres: MacGibbon \& Kee, 1964, p. 17.

3 Carlos Ribeiro Furtado. Gentrification e o processo de (re)estruturação urbana recente em Porto Alegre. In: PANIZZI, Wrana \& ROVATTI, João F. Estudos urbanos: Porto Alegre e seu planejamento. P. Alegre: Ed. da Universidade/UFRGS/ Prefeitura Municipal de Porto Alegre, 1993, p. 99-105. 
referentes à arquitetura militar, obra que reforçaria a tradição pragmática portuguesa no traçado urbano. ${ }^{4}$ Lembra-se que as cidades portuguesas tradicionalmente apresentam-se divididas em dois setores: a cidade baixa, para atividades portuárias e de grande comércio; a cidade alta, para as residências mais importantes, para o comércio varejista, para edifícios administrativos e religiosos. ${ }^{5}$

Depois da década de 1870, em Porto Alegre implantaram-se linhas regulares de transporte urbano, visto que as distâncias aumentavam. Antigos arraiais eram incorporados, assim como estradas que davam origem a arrabaldes: Menino Deus, Cidade Baixa, Floresta, São João, Navegantes. Registra Macedo que aspectos geográficos, históricos e econômicos haviam contribuído para a formação de três grandes setores urbanos que, por sua vez, influíram no surgimento de bairros; "[...] o setor primário - agricultura e pecuária - ao sul; o secundário - industrial - ao norte e o terciário - administração e comércio - no vale do Arroio Dilúvio, área central [...]"."

Por muito tempo a cidade apresentaria aspectos herdados do período colonial, mas a mudança fisionômica começava, com a paulatina incorporação de elementos arquitetônicos cosmopolitas, com traços do estilo renascentista e do nouveau.

O Centro era o espaço das sociabilidades públicas e, antes que uma reordenação global fosse promovida, fez-se da Rua da Praia um boulevard. Pois era ali que havia a maior concentração de estabelecimentos comerciais. Em 1895, dos 286 estabelecimentos registrados, 161 são identificados com segurança por seus proprietários com sobrenome estrangeiro, descontados aqueles que evidenciam sobrenomes lusos. Com proprietários de origem italiana estão registrados 78 estabelecimentos; 48 são alemães, 22 denunciam origem francesa, árabe, judaica, polonesa, espanhola ou grega; há 13 sobrenomes estrangeiros cuja origem não pode ser identificada. A maioria destes estabelecimentos, entretanto, são considerados de pequeno porte,

4 Paulo Varela Gomes. O essencial sobre a arquitetura barroca em Portugal. Porto: Faculdade de Arquitetura da Universidade do Porto, 1995, p. 14.

5 Luiz Fernando Rodhen. O traçado português no Brasil Meridional: origem e evolução - 1737-1777. (Dissertaçāo de Mestrado) P. Alegre: IFCHPUCRS, 1996, p. 89.

Francisco Riopardense de Macedo. Porto Alegre: história e vida da cidade. Porto Alegre: Universidade Federal do Rio Grande do Sul, 1973, p. 223. 
além de apresentarem grande diversidade: botequins, quitandas, oficinas de conserto de calçados, açougues, barbearias, tavernas, cigarrarias, armarinhos, casas de pensão, estofarias, padarias, oficinas de conserto de relógios, correarias, atelier de modistas e de alfaiates. ${ }^{\text {? }}$

Os antigos largos haviam sido remodelados, transformaram-se em praças. A Praça da Matriz encontrou-se embelezada com a inauguração dos edifícios da Câmara e do Tribunal de Júri, que faziam belo conjunto com o prédio do Theatro. O largo do Arsenal passara por processo de aformoseamento, tornando-se a Praça da Harmonia, onde se plantaram árvores e se colocaram bancos de madeira para o recreio da população.

População que aumentava rapidamente, diga-se de passagem. $\mathrm{O}$ censo de 1872 apontara cerca de 44 mil almas; em 1890 já eram quase 74 mil. Os habitantes triplicaram desde 1848 e a imigração foi o fator de maior importância.

Referindo-se a 1827, Seidler registrou que Porto Alegre era o melhor mercado para São Leopoldo e que o comércio de trânsito para o Rio de Janeiro enriquecia a cidade. Notou que muitos eram os ingleses e franceses nela domiciliados, cultivando hábitos de consumo que animavam a atividade produtiva dos alemães. ${ }^{8} \mathrm{O}$ soldado Hörmeyer, descrevendo a cidade em 1850, destaca a presença de seus conterrâneos e esboça Porto Alegre como cidade germanizada." Também Saint-Hilaire assinalara a influencia dos alemães na capital do Rio Grande do Sul.

Nos últimos anos do século XIX, acelerou-se o processo de industrialização, coincidindo com a mudança do regime político. Porto Alegre concentrava capital comercial, desenvolvia mercado consumidor e mercado de trabalho livre. Sediou então o maior número de fábricas do estado e a maior diversidade industrial. A produção industrial porto-alegrense esteve, sobretudo, vinculada ao mercado regional e foi financiada por capitais gerados através do comércio. Na maioria das vezes, resultou de pequenos capitais acumulados pela poupança de imigrantes.

7 Arquivo Histórico de Porto Alegre. Secretaria da Intendência - Imposto de Comércio pelo Valor Locativo - 1895, p. 1 a 8.

8 Carl Seidler. Dez anos no Brasil. B. Horizonte/S. Paulo: Itatiaia/Ed. da Universidade de Sâo Paulo, 1980, p. 121.

9 Joseph Hörmeyer. O Rio Grande do Sul de 1850. Porto Alegre: Luzzatto/Edunisul, 1996. 
Bucelli, viajante italiano observando a cidade em 1906, reconhece que a indústria surgira e se desenvolvia a partir da iniciativa de imigrantes alemães. O autor descreve a rua Voluntários da Pátria, detalhando os estabelecimentos comerciais e industriais que ali encontrou. No início da mesma rua localizavam-se casas comerciais de exportação, assim como aquelas atacadistas de gêneros alimentícios. Em seguida, encontravam-se os estabelecimentos industriais: fábricas de máquinas, de cerveja, móveis, tecidos, pregos, gravatas, espartilhos, etc. Destaca algumas destas fábricas pelo grande porte. É o caso da Fundição Berta, da fundição e estaleiro José Becker; da empresa Viúva Gustavo Hugo, especializada na fabricação de cofres, fornos, etc.; das firmas de Luís Rothfuchs e de Adolpho Kraemer, ambas especializadas na fabricação de carros para tração animal. Comenta sobre a produção da cervejaria Christoffel, sobre as fábricas de móveis e esquadrias de Francisco Herzog e de Germano Steigleder. Destaca também o moinho de Kessler, Dexheimer e Issler, assim como a fábrica de móveis de Einloft. ${ }^{10}$

Em conseqüência da industrialização, imigrantes alemães continuavam sempre chegando, assim como chegavam descendentes, saindo das colônias que se tornavam exíguas. Dividiam o espaço urbano com estrangeiros de outras etnias, que aportavam atraídos pelo crescimento da cidade e pelas oportunidades que a mesma oferecia. Eram poloneses e russos, árabes, portugueses, espanhóis, principalmente italianos que, entre 1875 e 1914 , formaram os maiores contingentes no Rio Grande do Sul, perfazendo o número aproximado de cem mil indivíduos. $\mathrm{O}$ grande número de estrangeiros que se fixou em Porto Alegre, entretanto, não pôde ser absorvido pela incipiente industrialização; o pequeno comércio e o setor de serviços continuaram crescendo através destes estrangeiros, como a documentação existente permite concluir. Registra Durhan que estudos sobre urbanização na América Latina "têm demonstrado que o crescimento das cidades se dá através da enorme expansão das atividades terciárias”; conclui a autora sobre a incapacidade do setor industrial em absorver a grande mão-de-obra disponível. ${ }^{11}$

10 Vittorio Bucelli. Un viaggio a Rio Grande del Sud. Milāo: Pallestrini, 1906, p. 100-106.

1 Eunice Durhan. A caminho da cidade. S. Paulo: Perspectiva, 1978, p. 46. 
Porém Porto Alegre, mais do que confluência econômica, tornarase confluência cultural, apresentando imagens que refletiam relações sociais condicionadas por diferentes grupos humanos. Canevacci registra que uma cidade se comunica através de diferentes vozes e que passa a ser narrada por coro polifônico. A materialidade da comunicação é determinada pelas relações sociais e culturais, sendo que grupos étnicos propiciam manifestação de diferenças. ${ }^{12}$

Tal polifonia é detectada à simples leitura de um caso de polícia, que resultou em processo criminal, tramitando no Tribunal do Júri em 1881. Serve como exemplo, fornece indícios para inúmeras inferências e pode ser resumido em poucas linhas. ${ }^{13}$

Carlo Rosa entrou na residência de Virginia Nerone, perguntando pela criada Rosa; não obtendo a informação desejada, insultou a dona da casa. Valério da Costa Ferreira, que se encontrava no interior da mesma casa, tratou de defender Virginia e foi agredido fisicamente pelo invasor. A vítima caiu e teria sido de novo agredida, não fosse a interferência de Antonio Crivellaro, que se encontrava nas imediações. Outras testemunhas prestaram depoimento no decorrer do processo: Frederico Berger, Maria Garnier e seu filho, Antonio Zeferino da Rosa e Carlos Stann.

Nesta pequena amostra, a diversidade dos sujeitos reflete o fenômeno que se verificava na cidade. Apenas dois personagens são naturais da província: Valério, a vítima e o sargento da Força Policial, Antônio Zeferino. Dentre as pessoas citadas no processo há um espanhol, um austríaco, um alemão. Os italianos são maioria: o acusado, a dona da casa onde se verificou a agressão, a criada Rosa, Maria Garnier e seu filho Carlos, o apartador Antonio Crivellaro. É possível concluir que estes estrangeiros são gente humilde, com pouco tempo de permanência na cidade. Com relação aos italianos, percebe-se que ainda não pertencem a grupo existente em Porto Alegre desde meados do século XIX.

Entre 1850 e 1880, há comprovadamente 40 famílias na cidade, formando grupo que se identifica e é identificado como italiano. Seus representantes encontram-se unidos por laços de compadrio e fundam

12 Massimo Canevacci. A cidade polifônica: ensaio sobre a antropologia da comunicaçāo urbana. S. Paulo: Nobel, 1993, p. 15.

13 Processo n.1422. Tribunal do Júri. Maço 54. Arquivo Público do Rio Grande do Sul. 
sociedade de mútuo socorro, em 1877. Como a maioria dos imigrantes, exercem atividades comerciais, são pintores, escultores, músicos ou fotógrafos. ${ }^{14}$

Mas em 1884, o Cônsul Pascale Corte afirma que todas as profissões já estão representadas entre os súditos do Reino d'Italia nas cidades rio-grandenses. Há diversos médicos, farmacêuticos, alguns engenheiros, muitos padres e comerciantes, até mesmo atacadistas. Lembra que há artistas plásticos de considerável mérito, bom número de fotógrafos, professores de canto e música, hoteleiros e donos de botequins. Lamenta a escassez de grandes fortunas, lembrando que a "colônia" recém alcançava um número significativo. Assinala ainda a presença de carpinteiros, estanhadores, caldeireiros, moleiros, padeiros, jardineiros, carroceiros e vendedores ambulantes, sublinhando que pouquíssimos trabalhavam para patróes. ${ }^{15}$

A criada Rosa teria sido um desses poucos indivíduos, visto que se empregava para serviços domésticos, tendo como patroa Virginia que se declarou viúva, vivendo de rendimentos. Já o réu Carlo Rosa é solteiro, padeiro e proprietário de hotel. Carlos Garnier e Crivellaro, ambos solteiros, declaram-se jornaleiros; Carlos Stann, natural da Alemanha, diz ser charuteiro.

A amostra é representativa. Sabe-se que a imigração urbana é predominantemente espontânea. Com referência ao italiano meridional, também em geral foi agricultor na província de origem, seja meeiro ou pequeno proprietário. Entretanto, tendo aprendido algum ofício, emigra para cidades onde possa exercê-lo. Em grande maioria emigra sozinho e solteiro, atendendo chamamento de algum parente. Como imigrante recém chegado pode até trabalhar por jornada, mas são as atividades ligadas ao comércio que em seguida exercerá. ${ }^{16}$

Tais características estão presentes na grande maioria de imigrantes urbanos e nossa pequena amostra torna-se mais uma vez exemplar. Os estrangeiros do sexo masculino envolvidos no processo

14 Núncia Santoro de Constantino. Italianos nos núcleos urbanos e na capital do Rio Grande do Sul. Estudos Ibero-Americanos, P. Alegre: PUCRS, v. XII, n. 1, jul. 1986.

15 Pascale Corte. Le colonie agricole nella provincia di Rio Grande del Sud nel Brasile all'Esposizione Nazionale de Torino. Montevidéu: 1892. Biblioteca del Ministero degli Affari Esteri d'Italia, Roma.

16 Núncia Santoro de Constantino. Immigranti Calabrese a Porto Alegre. Daedalus, Castrovillari, n. 1, jul.-dez. 1988. 
são homens solteiros e jovens, com idade que varia entre 14 e 19 anos. Pela declaração de domicílios, percebe-se que são vizinhos, habitando nas imediações da Praça da Harmonia, sítio da cidade onde se concentrou uma população de baixa renda.

Desde o início aquela área fora desprestigiada, pois circundava o local em que se erigiu a forca. Saint-Hilaire, observando a cidade na década de 1820 , registra que "[...] embora construída somente no lado noroeste da colina, a cidade possui várias casas no lado oposto, esparsas e desalinhadas, entremeadas de terrenos baldios, pequenas e mal construídas, quase todas habitadas pela população pobre". ${ }^{17} \mathrm{Na}$ extremidade do promontório, uma faixa de terra conhecida como Praia do Arsenal, encontrava-se voltada para oeste. Lembra Coruja que, "do lado do rio havia umas duas ou três casinhas de capim que serviam de moradia a gente pobre". ${ }^{18}$ Sanhudo, referindo-se às imediações do Largo do Arsenal, escreve que por ali havia estaleiros e casebres da população pobre. ${ }^{19}$

Em 1858, iniciadas obras para remodelação do Largo do Arsenal, o Presidente da Província justificava a iniciativa, alegando que "o distrito onde esta praça e cais se estão construindo serve em geral de residência às classes pouco abastadas e pobres" e que, por isso, pretendia "restaurar tais bairros e distritos e melhorar sua situação". ${ }^{20}$ Pode-se afirmar que grande parte da população pobre da cidade vivia nas imediações, no final do século, incluindo imigrantes italianos, que chegavam anualmente em número maior que aqueles de outras etnias. Os novos contingentes, portanto, ocupavam terrenos da Cidade Baixa. Outra área caracterizada pela pobreza era aquela contígua à Várzea, depois Campo da Redenção, cujos terrenos, considerados insalubres, iriam fazer parte do bairro Bom Fim.

Nas cidades baixas, tradicionalmente, alojavam-se populações de baixa renda. $\mathrm{O}$ zoneamento residencial porto-alegrense, a exemplo de outras cidades pré-industriais, revelou a mesma segregação. Reforça

17 Auguste Saint-Hilaire. Viagem ao Rio Grande do Sul: 1820-1821. Belo Horizonte/S. Paulo: Itatiaia/EDUSP, 1974, p. 41.

18 Antônio Alvares Pereira Coruja. Antigualhas: reminiscências de Porto Alegre. P. Alegre: ERUS, 1983, p. 109.

19 Ari Veiga Sanhudo. Porto Alegre: crônicas da minha cidade. P. Alegre: IEL/UCS, 1979 , p. 18.

20 Apud Sérgio da Costa Franco. Porto Alegre: guia histórico. P. Alegre: Ed. da Universidade/UFRGS, 1992. 
Géa que as habitações mais pobres encontravam-se "em zonas menos privilegiadas tais como as baixadas próximas a Ponta da Cadeia e em outras áreas insalubres sujeitas a inundações". A mesma autora assinala que as elites, no decorrer do século XIX, acomodaram-se na rua Duque de Caxias, centro do prestígio e de seus elementos simbólicos, como a Igreja Matriz e o Palácio do Governo. ${ }^{21}$

$\mathrm{Na}$ rua Duque, "a mais nobre da cidade", moravam as famílias tradicionais. Ali residiu a Viscondessa de Pelotas, os Chaves Barcelos, o dr. Possidônio da Cunha, o Dr. Borges de Medeiros. ${ }^{22}$ Mas, já em 1901, parte das propriedades encontra-se com imigrantes ou descendentes: Ratto, La Porta, Anello, Krieger, Blasmann, Lindstram, Salvatori, Threphen, Schmidt, Hasling, Puldner e Sirangelo pagam impostos correspondentes. Há também o registro de um cortiço, pertencente a Cristiano de Almeida Lemos, sob numeração de 6 a 12. ${ }^{23}$

Percebe-se que é alta a incidência de moradias humildes nas ruas do Centro. Em 1901, na Barros Cassal, Luis Antonello, Santino Longoni, Angelo Signor, Maria Soares, Manoella Lisboa, João Carlos Bastian, Frederico Pedro, Victor de Souza, José Gomes da Costa e Luis Grossi pagam impostos sobre a propriedade de cortiços. Na rua Fernando Machado, Joaquim Alves, Manoel da Silva Braga, Raphael Antonio Affonso e Antonio da Costa Rocha também pagam impostos correspondentes ao mesmo tipo de propriedade, além daqueles contribuintes que pagam impostos na categoria casa-de-pensão. ${ }^{24}$

No final do século teve início a ocupação mais efetiva da rua Independência, também situada em zona alta que "se firmou como área residencial da elite porto-alegrense que começava a buscar locais fora do centro da cidade". Géa, prosseguindo na análise desta ocupação, demonstrou que os moradores da rua ligavam-se à industria, ao alto comércio, às finanças, ou eram profissionais liberais de prestígio, "geralmente imigrantes ou filhos de imigrantes, alemães, italianos, portugueses, estes homens bem sucedidos se tornavam exemplo a ser seguido". Dentre os industriais cita Renner, Grecco, Bier, Antunes,

21 Lúcia Segala Géa. O espaço da casa: arquitetura residencial da elite portoalegrense (1893-1929). P. Alegre, 1995. Dissertação de Mestrado em História, PUCRS, p. 72.

22 Sérgio da Costa Franco. "Apresentação". In: TOSTES, Theodomiro. Nosso Bairro: memórias. P. Alegre: Fundaçāo Paulo do Couto e Silva, 1989, p. 9.

23 Arquivo Municipal de Porto Alegre. Cobrança de Impostos, Livro n. 43 p. 31 a 40.

24 Id., Ibid., p. 28-29-30-31; 45-46-47-48. 
Gerdau, Chaves Barcelos; no setor comercial, registra como moradores Torres, Daudt, Dreher, Marino, Sperb, Becker, Dexheimer, Graether, Pötzel, Iken, Barros, Bergmann, Saraiva. ${ }^{25}$

Os primeiros estabelecimentos industriais de grande porte estiveram localizados na rua Voluntários da Pátria. Suas transversais e próximas paralelas foram ruas preferenciais aos trabalhadores, concentrando assim um grande número de alemães e descendentes. Estes passaram a ocupar áreas em torno de dois dos principais eixos de expansão da cidade para o norte, ou seja, a própria Voluntários, que conduzia ao arraial de Navegantes e a rua da Floresta, limitando área que deu origem a três bairros: Floresta, São João e Navegantes, os dois últimos formando o $4^{\circ}$ distrito.

Toma-se como referência a rua Cristóvão Colombo, ou antiga rua da Floresta, em 1900. Percebe-se que há proprietários com mais de um imóvel na mesma rua. É o caso de Theodoro Guinsreld, Adolpho Fick, Guilherme Becker, Ernesto Slick, Mathilde Goedens, Carlos Bopp, Ernesto Brokmann, André Raupp, Augusto Goebel, Jacob Winter, Virginia Meyer, Frederico Weishand, Giacomo Massaia, Nicolau Juliano, Rainier Luciano, Eduardo Hillig, João Deistmann, João Paternoster, Lourenço Miraglia, Maria Amalia Fetter. É lógico supor que, neste rol, haja muitas propriedades destinadas a aluguel. Explícita, entretanto, é a existência de cortiços, sobre os quais são cobrados impostos, segundo o número de habitações que os mesmos contêm. Entre 273 proprietários que recolhem estes impostos, sete possuem 28 cortiços. Constata-se, entretanto, que é significativa, na mesma rua, a incidência de sobrados ou assobradados, cerca de 5\% dos imóveis, propriedades de Wendesch, Becker, Bopp, Brockmann, Raupp, Mayer e Miraglia. $^{26}$

Tomando-se a rua Gen. Neto, encontra-se 36 proprietários recolhendo impostos no mesmo ano. Seis detêm mais de uma propriedade, há outros cinco proprietários que recolhem sobre cortiços. ${ }^{27}$

Pelo eixo da rua Voluntários da Pátria, verifica-se aleatoriamente uma rua perpendicular, correspondente ainda ao bairro Floresta. Na rua Hoffman, em 1900, são registrados 30 proprietários e 14 têm sobrenome alemão; destes, seis têm mais de uma propriedade na mesma

25 Lúcia Segala Géa, op. cit., p. 47, 25, 27.

${ }^{26}$ Arquivo Municipal de Porto Alegre. Cobrança de Impostos, Livro n. 38, p. 1 a 5.

27 Id., ibid., Livro 38 , p. 14 e 15. 
rua. ${ }^{28}$ Quanto à rua Gen. Netto, por exemplo, em 1910, entre 36 contribuintes, 18 têm sobrenomes alemães, ou seja, 50\%. O mesmo percentual repete-se á rua Dr. Vale e à rua Hoffmann.

O eixo da Cristóvão Colombo prolonga-se pela rua Benjamin Constant, alcançando o bairro São João. Nesta rua, mais de $10 \%$ dos proprietários têm sobrenome alemão, percebendo-se também uma alta incidência de sobrenomes de origem italiana. A incidência de nomes alemães aumenta nas ruas transversais, como é o caso da Berlim e da Cairu. Na primeira, cerca de $30 \%$ dos proprietários têm origem alemã; na segunda, dentre 46 proprietários, 18 evidenciam a mesma origem e seis têm sobrenomes poloneses. Na Av. França, também transversal, em 1900 há dezoito proprietários pagando impostos, nove indicam origem alemã e três indicam polonesa. ${ }^{29}$

Retomando o eixo da Voluntários da Pátria em direção a Navegantes, analisa-se a Rua São Pedro, transversal que corta o bairro São João, até a Benjamin Constant, e a Av. Eduardo, paralela à Voluntários. Na primeira, recém aberta em 1900, ainda há muitos terrenos da Cia. Territorial Porto Alegre, responsável pelo loteamento. De onze proprietários arrolados, cinco denunciam origem italiana, dois têm nomes alemães e dois são poloneses. Dentre os de origem alemã, Augusto Nöher paga imposto sobre onze propriedades. Na Av. Eduardo, onde está concentrado o comércio da zona, a propriedade concentra-se em sobrenomes italianos; Felipe Laporta, Mascini, Prescistullo, Favere, Graci e Piovani pagam impostos por mais de três propriedades. Há alta incidência de sobrenomes alemães, como Young, Host e Müller, também responsáveis por mais de três imóveis. Indício de acumulação de capital é a presença de Guimbitzki, conhecido proprietário de origem polonesa, que paga impostos sobre dois imóveis na Av. Eduardo. ${ }^{30}$

Outras transversais à rua São Pedro ratificam tendências. São ruas loteadas pela Cia. Territorial Porto-Alegrense, a partir de 1895 . Na Av. Pará, por exemplo, há apenas nove imóveis que pagam impostos, pertencentes a cinco indivíduos; destes, 4 têm sobrenome alemão e um tem sobrenome italiano. A Amazonas tem quatro pagadores de impostos, além da Cia. Territorial Porto-Alegrense; 3 têm nomes ale-

\footnotetext{
28 Id., ibid., Livro 40, p. 45.

29 Id., ibid., Livro 40, p. 64-66, p. 61, p. 54.

30 Id., ibid., Livro 40, p. 69, 57-8.
} 
mães e um tem nome de origem lusa. Quanto a paralelas, veja-se a Av. Polônia: dos 12 imóveis registrados, dez têm proprietários de origem alemã e um denuncia origem italiana. Na Ernesto Fontoura, há 31 proprietários registrados; apenas Fulginitti é de origem italiana, enquanto Tullert, Pischlz, König, Lampert, Litz, Assmann, Richve e Boese são de origem alemã. Mageviski, Gevinski, Snevalski, Dulisck são proprietários de origem polonesa conhecida. ${ }^{31}$

Ainda pelo eixo da Voluntários, chega-se a Navegantes, cuja artéria principal é a Sertório. De 51 proprietários, 16 têm sobrenomes alemães.

Na Cidade Baixa, verificando-se a rua José do Patrocínio, em 1900, constata-se que, entre 173 propriedades, apenas duas pertencem a indivíduos com sobrenome italiano: Fusquini e Baldino. Na João Alfredo, entre 42 proprietários que recolhem impostos, seis denunciam a origem italiana: Tortorelli, Alberti, Frasca, Menelli, Ratto (Angelica e João Carlos). Na rua da República, entre 77 propriedades, apenas uma pertence a contribuinte de origem italiana: Viale. Entre 123 contribuintes da rua Avahy, Tubino e Obino são os únicos com sobrenome italiano. À rua Demétrio Ribeiro, observa-se uma concentração maior de proprietários italianos meridionais, em determinada quadra, já em 1901: Carlucci, Curcio, Faillace, Suttei, Ratto, Anello. ${ }^{32}$ Importante destacar a incidência de cortiços nestas ruas da Cidade Baixa. São proprietários do mesmos: Appolinario Caldas, André Barboza, Manoel Bento, Antonio Correa Dias de Moura, Ignacio Antonio da Silva, José Antonio Portella, José Jacintho Coelho, Eulino Ribeiro, Carlos Carlucci, Joaquim de Oliveira Alves. ${ }^{33}$ Nada que se compare, entretanto, com a incidência verificada na Rua Baroneza do Gravataí, desde o loteamento, em 1879, zona de habitações populares, sobretudo de moradias de negros libertos. Nesta rua, em 1901, entre 76 propriedades, pagam impostos cinco cortiços, pertencentes a Amandio Pereira, Giuseppe Batiston, Francisco Pezzet e a Propício Magalhães. ${ }^{34}$

Em 1920, percebe-se mudanças significativas. Na Rua José do Patrocínio, entre 191 proprietários que pagam impostos, cerca de $10 \%$

\footnotetext{
31 Id., ibid., Livro 40, p. 59, 92, 87.

32 Id., ibid., Livro 43, p. 54 a 59.

33 Id., ibid., Livro 37, p. 41 a 58.

34 Id., ibid., Livro 43, p. 53.
} 
têm sobrenomes italianos que designam conhecidas famílias, principalmente de origem italiana meridional: Longo, Marroni, Schiffino, Faillace, Mancuso, Orsi, La Porta e Ciulla. O índice se mantém com relação às ruas João Alfredo e Avahy, assim como a tendência de sobrenomes meridionais. Na rua Demétrio Ribeiro, observa-se fenômeno semelhante, sempre no ano de 1920, com acréscimo significativo de proprietários de origem meridional italiana, como Schiffini, Celiberti, Guaragna,Vittola, Ferrari, Medaglia, Di Lorenzo, Rosito. Nesta última rua, verifica-se a permanência de cortiços, dos quais são proprietários Manoel Esteves, Gedeon Leite, Ernestina de Barros, Luiza Portella. ${ }^{35}$

Comparando-se os imóveis pela especificação ao imposto devido, também verifica-se que houve melhoria na qualidade dos mesmos. $\mathrm{Na}$ rua José do Patrocínio, por exemplo, em 1900 só há registros de casas térreas; em 1920 já aparecem casas assobradadas, propriedades de Miguel Sasso e de Francisca Orsi.

Como foi dito, a área fronteira à Várzea, que deu origem ao Bairro Bom Fim, também foi zona desprestigiada. Em 1910, à rua João Telles, pagam impostos 133 proprietários. A julgar pelos sobrenomes estrangeiros, a incidência maior recai sobre italianos, com mais de $15 \%$, seguidos por sobrenomes de origem alemã, cerca de $6 \%$, todos, com exceção de um contribuinte, Santa Helena, pagando impostos na categoria de casas térreas. À mesma rua, em 1920, há registro de quatro sobrados e mantém-se o percentual relativo a proprietários de origem italiana. Mas naquele ano, aparecem como proprietários os primeiros nomes de imigrantes judeus: Henzelman, Wulf, Pargendler, Schlatz, Suslik. A mesma tendência é verificada na rua Felipe Camarão, uma das mais importantes do Bom Fim. Destaca-se neste bairro, igualmente, a existência de muitos cortiços, como aqueles de propriedade de Juvenal Ribeiro, da Cia. Riograndense, de Alberto Travi, Balthazar Scalco, Olinto Alves Pinto, Cecilia Steigleder, Felippe Diefenthäeler, Izabel Doering, Diogo de Souza Rodrigues, Giacomo Spolari, Regina Paganini, Emilio Adam e Italo Parussini ${ }^{36}$ Como bairro desprestigiado socialmente, recebeu grande número de imigrantes, num primeiro momento predominantemente italianos, a partir da dé-

\footnotetext{
35 Id., ibid., Livro 167.

36 Id., ibid., Livros 40, 88, 162, 167.
} 
cada de 1920, preferencialmente judeus, que ali desenvolveram importante zona comercial.

Faz-se necessário destacar que, nas primeiras décadas do século, houve grande aumento no número de construções licenciadas na cidade. Em 1900 foram 266, em 1905 houve 384 licenciamentos, em 1910, 887; os números caem em 1915 para 294; em 1920 sobem para 390 e, em 1925 são 1228, número que se mantém aproximado em 1930, quando as construções de madeira representam mais do que o dobro daquelas de alvenaria, indicando a expansão de casas populares. Sérgio da Costa Franco fornece outros dados de fundamental importância.

Entre 1899 e 1903, demonstra o autor citado, 53\% das construções licenciadas são em alvenaria; no período seguinte, até 1908, são 64\%; o percentual cai para 59\% até 1913 e aumenta para $72,95 \%$ entre 1914 e 1918; a partir de então o percentual apresenta queda, isto é, são 56,7\% entre 1919 e 1923, 46\% entre 1924 e 1928. O caráter das moradias populares fica bem acentuado quando há cálculo relativo às áreas licenciadas. No período entre 1899 e 1903, 82\% da área é licenciada para 53\% de casas em alvenaria; entre 1904 e 1908, 79\%, para 64\% de casas em alvenaria; entre 1909 e 1913, o percentual em área alcança $69 \%$, para $60 \%$ de casas do mesmo material. Nos períodos subsequentes, até 1928 , a média percentual será de $78 \%$ para áreas em construções de alvenaria, cuja média percentual é de $59 \% .{ }^{37}$ Há, portanto aumento significativo no número de construções populares, de madeira, que chegam a suplantar as de alvenaria no último período, construções que ocupam terrenos de pequenas dimensões.

A amostragem de dados colhidos permite algumas inferências e muitas intuições, como se espera de um estudo exploratório.

Em primeiro lugar, tratando-se de gentrification, na acepção que o termo vem apresentando, nada leva a crer que, no início do século, tal processo tenha ocorrido. Bem mais adequadas para o período focalizado são as ferramentas teóricas da Sociologia, quando trata de estrutura e estratificação social. É também importante considerar a variável cultural, pois imigrantes evidenciam ambição visceral de ascender socialmente; o acesso à propriedade é uma meta. Solteiros e pobres, residiram em pensões baratas e nos cortiços localizados nas

37 Sérgio da Costa Franco. Porto Alegre - construçōes licenciadas. Fonte: Relatórios de Intendentes Municipais (1899-1932). Tabela mimeografada. 
imediações dos locais de trabalho, procurando a proximidade com conterrâneos. A casa própria, entretanto, é ideal extremamente generalizado, tendo valor instrumental; é forma de obter uma certa segurança econômica. A propriedade de terrenos nos loteamentos em $\mathrm{Na}$ vegantes e São João, preferencialmente por imigrantes alemães ou descendentes, nas proximidades das fábricas, assim como a construção das modestas casas que caracterizaram os respectivos bairros, é clara evidência do processo.

A partir dos dados colhidos, intui-se que a transformação de zonas populares em bairros de classe média deve-se sobretudo a um movimento que aponta para melhorias, através de intervenções que transformam a estrutura do bairro, acompanhando portanto exigências decorrentes da mudança de posição social dos seus moradores. Em se tratando de imigrantes, a etnicidade pode ser um "poderoso veículo organizatório [...], pode ser a armação interna das relações de produção", como registra Carneiro da Cunha. ${ }^{38}$ Tal etnicidade torna-se instrumental para confirmar lideranças e posicionar indivíduos num esquema de classificação social mais satisfatório do que a classificação baseada em critérios de simples distribuição da renda.

A esta altura, emerge a questão do espaço semantizado, mantendo relação direta com indivíduos e alimentando também relação direta com o seu imaginário. Basta lembrar que há uma carga afetiva, inerente à toda vivência no espaço. A semantização inicial do espaço depende de uma ideologia e das relações sociais que no mesmo historicamente se verificaram. A ideologia que aponta para o estrangeiro como honesto e pacífico, indivíduo capaz de progredir pelo trabalho árduo, reforça e é reforçada no espaço em que vive o imigrante. Freqüentemente é verbalizado que Floresta e Cidade Baixa são bairros da boa classe média, porque, respectivamente, são espaços de alemães e italianos.

O Bom Fim, zona desprestigiada no período analisado, continuou recebendo imigrantes até a década de quarenta, sendo que os últimos fluxos foram constituídos por judeus, num primeiro momento egressos de colônias fundadas no interior do Estado e, em tempos mais recentes, provenientes da Europa em conseqüência da Segunda Guerra.

38. Manoela Carneiro da Cunha. Antropologia do Brasil: mito, história, etnicidade. S. Paulo: Brasiliense/EDUSP, 1986, p. 99-106. 
Já Navegantes e São João foram sendo progressivamente ocupados por instalações industriais que cedem espaço, também paulatinamente, a estabelecimentos comerciais de grande porte. De modo especial em Navegantes, as possibilidades de áreas residenciais foram bloqueadas, com a construção do complexo viário da ponte sobre o Guaíba e pela expansão do porto. Assim, constata-se até mesmo o sucateamento de quarteirões residenciais operários, em áreas contíguas a grandes fábricas, na maioria desativadas. Restam alguns quistos residenciais que se apresentam como típicos da classe média, especialmente em área desmembrada que constitui o bairro São Geraldo. Entretanto, permanecem na zona que constituiu o quarto distrito da cidade, suas principais referências, como associações e templos religiosos. É o caso da Sociedade Polonesa, da Sogipa, da Sociedade Gondoleiros; da Igreja de Nossa Senhora dos Montes Claros, com culto em polonês, das igrejas ortodoxas russa e ucraniana; de vários templos católicos e protestantes. Outro fenômeno a assinalar é o deslocamento de muitas famílias que ascenderam socialmente, para área confinante e mais alta, área que, também desmembrada, passou a fazer parte do bairro Higienópolis.

No que diz respeito ao grupo social alemão, percebe-se clara diferenciação. É grupo estratificado, há complexa hierarquia que se desenvolve em função dos desempenhos econômicos. A diferenciação espacial entre locais de moradia constituiu evidência. Salienta-se que o capital acumulado decorre da antigüidade da imigração na cidade. São famílias há muito tempo residindo na mesma as que se deslocam para zonas de prestígio, como é o caso da Av. Independência. São famílias que chegaram em tempos mais recentes, alemãs ou descendentes, que se fixaram na zona norte, de alguma forma atraídas pelo desenvolvimento industrial da área.

Analisando-se espaços de imigrantes na cidade, ratifica-se que a imigração é um fenômeno social, mais do que individual. Determinados grupos permanecem articulados em função da vizinhança que, por sua vez, auxilia na rearticulação de relações primárias que compóem o universo de origem. Também em Porto Alegre verifica-se que o imigrante quase nunca é um indivíduo isolado, mas parte de um grupo primário que, dissolvido no outro lado do oceano, de alguma forma se reorganiza também pela ocupação de espaços. 